\title{
Sulfur(IV) assisted oxidative removal of organic pollutants from source water ${ }^{\text {tr }}$
}

\author{
Alexandra Truzsi ${ }^{a, b}$, János Elek ${ }^{c}$, István Fábián ${ }^{c, d, *}$

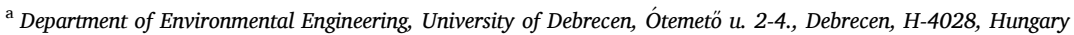 \\ ${ }^{\mathrm{b}}$ Doctoral School of Chemistry, University of Debrecen, Egyetem tér 1., Debrecen, H-4032, Hungary \\ ${ }^{c}$ Department of Inorganic and Analytical Chemistry, University of Debrecen, Egyetem tér 1., Debrecen, H-4032, Hungary \\ ${ }^{\mathrm{d}}$ MTA-DE Redox and Homogeneous Catalytic Reaction Mechanisms, Research Group, Egyetem tér 1., Debrecen, H-4032, Hungary
}

\section{A R T I C L E I N F O}

\section{Keywords:}

$\mathrm{S}(\mathrm{IV})-\mathrm{Fe}(\mathrm{II}) / \mathrm{Fe}(\mathrm{III})$-air system

Catalytic autoxidation

Oxysulfur radical ion

Chemical oxygen demand (COD)

Drinking water treatment

\begin{abstract}
A B S T R A C T
The removal of organic pollutants presents a major challenge for drinking water treatment plants. The chemical oxygen demand (COD) is essentially the measure of oxidizable organic matter in source waters. In this study, we report that COD can efficiently be decreased by adding $\mathrm{Fe}(\mathrm{II}) / \mathrm{Fe}(\mathrm{III})$ and sulfite ion to the source water while purging it with air. In this process, oxygen is activated to oxidize the main constituents of COD, i.e. organic substrates, via the generation of reactive inorganic oxysulfur radical ions. In the end, the total amount of sulfur (IV) is converted to the non-toxic sulfate ion. It has been explored how the COD removal efficiency depends on the concentration of S(IV), the total concentration of iron species, the concentration ratio of Fe(II) and Fe(III), the purging rate and the contact time by using source water from a specific location (Királyhegyes, Hungary). The process has been optimized by applying the Response Surface Methodology (RSM). Under optimum conditions, the predicted and experimentally found COD removal efficiencies are in excellent agreement: $85.4 \%$ and $87.5 \%$, respectively. The robustness of the process was tested by varying the optimum values of the parameters by \pm $20 \%$. It was demonstrated that the method is universally applicable because a remarkable decrease was achieved in COD, $62.0-88.5 \%$, with source waters of various compositions acquired from 9 wells at other locations using the same conditions as in the case of Királyhegyes.
\end{abstract}

\section{Introduction}

Groundwater is the most prestigious resource of drinking water in many parts of the world and its quality is a primary concern with respect to producing potable water (Jha et al., 2020). Organic compounds are the main common contributors to contamination in groundwater which can be of either natural or anthropogenic origin. Raw waters used for preparing potable water exhibit a wide range of chemical and physical properties. They can be rich in a variety of natural organic matter (NOM) such as humic substances (mostly fulvic acids), non-humic materials (e. g. proteins, carbohydrates, hydrocarbons) and contaminants from industrial activities (Schmoll et al., 2006). The presence of organic substances in raw water is associated with a number of challenges in drinking water treatment technologies. The high organic matter content has a negative impact on water quality due to color, taste, odor and toxicity problems, and also requires high doses of coagulation and disinfection agents (Matilainen and Sillanpaa, 2010). In addition, these compounds should be considered as the precursors in the formation of harmful disinfectant by-products (DBPs), such as adsorbable organic halides (AOXs) and trihalomethanes (THMs) (Baken et al., 2018; Franklin et al., 2021; Mazhar et al., 2020; Postigo et al., 2021; Xu et al., 2021). Finally, the high organic matter content may adversely affect the biological stability of drinking water, promote fouling in the distribution system and contribute to an increased level of heavy metal concentration via complex formation reactions (Huang et al., 2020; Latchmore et al., 2020; Pan et al., 2021).

In general, water quality is characterized by indicative 'sum' parameters like chemical oxygen demand (COD), biological oxygen demand (BOD), total organic carbon (TOC) etc. which are interrelated (Sun et al., 2020). COD is an empiric, easily accessible laboratory assay which measures mainly the amount of oxidizable organic matter (both biodegradable and non-biodegradable) because inorganic oxygen consuming

\footnotetext{
This paper has been recommended for acceptance by SU SHIUNG LAM.

* Corresponding author. Department of Inorganic and Analytical Chemistry, University of Debrecen, Egyetem tér 1., Debrecen, H-4032, Hungary.

E-mail address: ifabian@science.unideb.hu (I. Fábián).
} 
components are typically present at low concentration levels in source waters. Accordingly, the progress of the removal of organic pollutants can conveniently be monitored during water treatment by measuring COD. Water quality regulations set strict thresholds for certain contaminants of organic origin such as pesticides, trichloro- and tetrachloro-ethene and AOX (Council of the European Union, 2020; World Health Organization, 2018). The precursors of these contaminants are the main constituent of COD. Therefore, COD is an important quality indicator of ground and surface waters. For example, the United Nations Economic Commission for Europe (UN-ECE) classifies surface freshwater as class I, II, III, IV and V with COD values $<3,3-10,10-20$, 20-30 and $>30 \mathrm{mg} \mathrm{O}_{2} / \mathrm{L}$, respectively (United Nations Economic Commission for Europe (UN-ECE), 1993). In many national regulations the allowed upper limit for COD is set to $5 \mathrm{mg} \mathrm{O}_{2} / \mathrm{L}$ or less in drinking water.

In order to meet drinking water quality requirements, as well as, to prevent the formation of antagonistic products, the concentration of the organic components needs to be decreased in the first stage of water treatment technologies. Filtration, coagulation and oxidation methods have been used to achieve this goal (Gitis and Hankins, 2018; Kohler et al., 2016; Matilainen and Sillanpaa, 2010; Mtavangu et al., 2017; Noredinvand et al., 2016). Relatively high removal rate was realized by using strong oxidants such as $\mathrm{MnO}_{4}{ }^{-}, \mathrm{O}_{3}, \mathrm{H}_{2} \mathrm{O}_{2} / \mathrm{O}_{3}$ (Alsheyab and Muñoz, 2007).

In recent years, there has been growing interest in the oxidation of various substrates by oxysulfur radical ions. These oxidants are particularly versatile because of the low environmental impact and toxicity of sulfate ion formed from them. Beside peroxomonosulfate and peroxodisulfate ions, sulfur(IV) has extensively been used as a precursor for generating such radicals (Li et al., 2020; Stankov et al., 2021; Zhou et al., 2018). Depending on the $\mathrm{pH}, \mathrm{S}(\mathrm{IV})$ may predominantly exists as $\mathrm{SO}_{3}{ }^{2-}$ (alkaline $\mathrm{pH}$ ), $\mathrm{HSO}_{3}{ }^{-}$(neutral - acidic $\mathrm{pH}$ ), and $\mathrm{H}_{2} \mathrm{O} \bullet \mathrm{SO}_{2}$ (acidic $\mathrm{pH}$ ) in aqueous solution. These forms are involved in acid - base equilibria and exhibit different activities in redox reactions. As a consequence, the kinetics of these processes feature distinct pH-dependency. While S(IV) is considered as a reducing agent, in the presence of appropriate catalysts and dissolved oxygen it can be the source of strongly oxidizing species such as $\mathrm{SO}_{3}{ }^{\bullet-}, \mathrm{SO}_{4}{ }^{\bullet-}$ and $\mathrm{SO}_{5}{ }^{\bullet-}$ (Brandt et al., 1994; Chen et al., 2021; Guerra-Rodríguez et al., 2021; Kraft and van Eldik, 1989; Lente and Fábián, 2002; Nie and Xiao, 2020). The Fe(II)/Fe(III) catalyzed autoxidation of S(IV) has extensively been studied before. Thorough studies on the kinetics and mechanism of this reaction revealed that the reactive intermediates formed in this system may be suitable for the oxidation of organic compounds (Lente and Fábián, 2002). Most recent studies have confirmed that the amount of contaminants in simulated or real waste water can significantly be reduced by administering simultaneously iron in various oxidation states, S(IV) and air (Dong et al., 2020; Wang et al., 2020; Wu et al., 2021; Xiao and Yu, 2021; Xie et al.,
2019). So far, the combination of these reagents has not been used in drinking water technologies for removing COD. In this paper we provide a detailed account on reducing oxygen demand to well below the regulation limit in source water by the $\mathrm{Fe}(\mathrm{II}) / \mathrm{Fe}(\mathrm{III})$ - S(IV) - air system.

This study has been carried out on the basis of the following general considerations. The $\mathrm{Fe}(\mathrm{III}) / \mathrm{Fe}(\mathrm{II})$ catalyzed autoxidation of S(IV) is a complex, radical type chain reaction. The most relevant reaction steps of this process are listed in Table S1, and the outline of the mechanism is shown in Scheme 1(Brandt et al., 1994; Lente and Fábián, 2002).

First, $\mathrm{S}(\mathrm{IV})$ is oxidized by $\mathrm{Fe}(\mathrm{III})$ to the sulfite radical ion $\left(\mathrm{SO}_{3}{ }^{-}\right.$) in a rate determining step. This intermediate quickly reacts with dissolved oxygen to produce the peroxomonosulfate radical ion $\left(\mathrm{SO}_{5}{ }^{-}\right)$which is an extremely powerful oxidant. In fact, this step is responsible for the activation of the otherwise inert $\mathrm{O}_{2}$. In subsequent steps, $\mathrm{SO}_{5}{ }^{\circ-}$ reoxidizes $\mathrm{Fe}(\mathrm{II})$ to $\mathrm{Fe}(\mathrm{III})$, oxidizes $\mathrm{S}(\mathrm{IV})$ to $\mathrm{SO}_{3}{ }^{\bullet-}$ and involved in other reactions to generate $\mathrm{SO}_{4}{ }^{2-}$ and $\mathrm{SO}_{4}{ }^{\circ-}$. The sulfate radical ion also contributes to the oxidation of S(IV) and Fe(II). Provided that S(IV) is in excess, the redox cycling of iron between the two oxidation states and the overall catalytic process are sustained as long as $\mathrm{O}_{2}$ is present in the system. Once it is used up, Fe(III) is fully reduced to Fe(II) by S(IV) and the reaction terminates. The model also predicts that S(IV) is fully consumed and $\mathrm{Fe}(\mathrm{III})$ is not fully converted into $\mathrm{Fe}(\mathrm{II})$ when $\mathrm{O}_{2}$ is continuously replenished by purging the reaction mixture with oxygen or air.

When an oxidizable substrate is added to the system, its oxidation is coupled with the catalytic autoxidation process of S(IV), i.e. the substrate is oxidized by the reactive radicals via a parallel reaction path while $\mathrm{S}(\mathrm{IV})$ is simultaneously regenerated. Such oxidation reactions take place with the $\mathrm{SO}_{5}{ }^{\bullet-}, \mathrm{SO}_{3}{ }^{\circ-}$ and $\mathrm{SO}_{4}{ }^{\bullet-}$ radicals. The outcome of the overall reaction is determined by the interplay of the various reaction steps which is controlled by the experimental parameters, most importantly by the concentrations of the reactants. When this system is used for decreasing COD, the oxidation of the substrates needs to be considerably faster than the oxidation of S(IV) to S(VI). In order to provide sufficient amount of oxidant, oxygen needs to be replenished in the reaction mixture continuously. The activation of $\mathrm{O}_{2}$ stops when the total amount of S(IV) is consumed.

The above discussion describes only the general features of this system. In reality, several other processes may occur, such as the acidbase reactions of the reactants, the formation of various complexes between S(IV) and the catalyst. Under slightly acidic - neutral conditions, the formation of $\mathrm{Fe}(\mathrm{III})$ hydroxo precipitates is also evident, which opens a possibility for heterogeneous catalytic reactions. Thus, a rather complex reactive system prevails, and the examination of the intrinsic mechanism of the overall process is unfeasible. Now we pursue a practical approach which considers the general kinetic features but does not explore the individual reaction steps. Instead, we meticulously

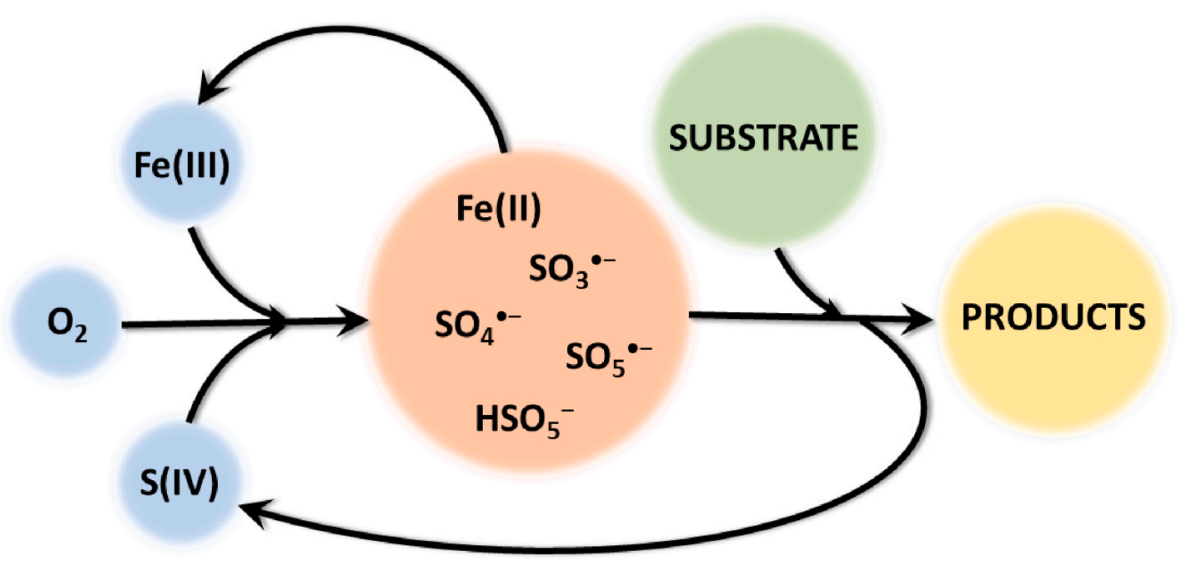

Scheme 1. The oxidation of a substrate by the Fe(II)/Fe(III) - S(IV) - air system. 
investigate how the variation of the concentrations of the reactants affects the efficiency of COD removal. Under technological conditions, the features of the input source water cannot be changed. Keeping this in mind, no attempt was made to alter the composition and, in particular, to set the $\mathrm{pH}$ of the samples in these studies. In other words, source waters were used as received from the wells. We use the Response Surface Methodology (RSM) for establishing the optimum conditions which make favorable the oxidation of the organic contaminants over that of S(IV).

\section{Materials and methods}

\subsection{Materials and water samples}

The source waters were obtained from deep-drilled wells at the following locations: Apátfalva, Biharkeresztes, Földeák, Királyhegyes, Kismarja, Makó, Nagyér and Pocsaj (Hungary). The relevant features of these source waters are provided together with some of the results in Table 2. Unless otherwise stated, all results were obtained by using source water from the well of Királyhegyes, (EOVy: 770635.8 m, EOVx: $104066.9 \mathrm{~m})$ which is characterized with relatively high COD $(7.02 \mathrm{mg} /$ $\mathrm{L})$. The other major characteristics of this raw water are as follows: 1.11 $\mathrm{mg} / \mathrm{L}$ ammonia, $97.5 \mu \mathrm{g} / \mathrm{L}$ iron, $22.1 \mu \mathrm{g} / \mathrm{L}$ manganese, $7.70 \mu \mathrm{g} / \mathrm{L}$ arsenic, $7.16 \mathrm{~L} / \mathrm{m}^{3}$ methane, $\mathrm{pH}=8.2$ and $18.5^{\circ} \mathrm{C}$ water temperature.

Reagents $\mathrm{Na}_{2} \mathrm{SO}_{3}$ (Sigma-Aldrich), $\mathrm{Fe}_{2}\left(\mathrm{SO}_{4}\right)_{3}$ (VWR Chemicals), $\mathrm{FeSO}_{4}$ (Reanal), $\mathrm{KMnO}_{4}$ (P.P.H. Polskie Odczynniki Chem.) $\mathrm{Na}_{2}(\mathrm{COO})_{2}$ (Reanal) were used in analytical grade quality without further purification. Synthetic air $\left(21 \% \mathrm{O}_{2}, 78 \% \mathrm{~N}_{2}\right.$ and $1 \%$ other $)$ was obtained from Linde.

\subsection{Analytical methods}

The COD of the samples was determined by the standard $\mathrm{KMnO}_{4}$ method (Geerdink et al., 2017).

The total consumption of sulfur(IV) in the oxidation reaction was confirmed by the lack of the corresponding peak in the ion chromatogram of the samples recorded with a Thermo Scientific Dionex ICS-5000 ion chromatographic system.

\subsection{Experimental design and optimization}

In a typical experiment, $250 \mathrm{~mL}$ raw water was added to a gas washing bottle equipped with a fritted disc. Synthetic air was introduced via the fritted disk from the bottom and a steady gas flow was established by utilizing a Gilmont correlated laboratory shielded flowmeter (Thermo Scientific). Subsequently, $\mathrm{Na}_{2} \mathrm{SO}_{3}, \mathrm{Fe}_{2}\left(\mathrm{SO}_{4}\right)_{3}$ and $\mathrm{FeSO}_{4}$ were added to the solution which led to the formation of a brownish precipitate. After a sufficient contact time, samples were withdrawn from the reaction mixture, filtered with a $25 \mathrm{~mm} 0.45 \mu \mathrm{m}$ Nylon Membrane syringe filter (VWR Syringe Filter) and analyzed for COD. First, the concentration dependence of the removal efficiency of COD was systematically studied by varying the concentration of one reactant and maintaining constant concentrations for the other ones. It was confirmed in repeated experiments that the experimental results are reproducible within $\pm 0.2 \%$. Finally, the results of these experiments were used as input parameters in the optimizing procedure performed with Response Surface Methodology (RSM) using RSM packages of Design Expert ${ }^{\circledR} 11.0$ (USA). Once the optimum parameters were established, their validity was confirmed in control experiments by applying the predicted reactant concentrations and reaction time. All experiments were run at room temperature, $\sim 25^{\circ} \mathrm{C}$.

\section{Results and discussion}

\subsection{The effect of experimental parameters on the COD removal efficiency}

According to preliminary experiments, the efficiency of COD removal by the $\mathrm{Fe}(\mathrm{II}) / \mathrm{Fe}(\mathrm{III})$ - S(IV) - air system greatly depends on the total concentration of $\mathrm{Fe}\left(c_{\mathrm{Fe}}\right)$, the relative concentration of $\mathrm{Fe}(\mathrm{II})$ ( $\mathrm{Fe}$ (II)\%), the concentration of sodium sulfite $\left(c_{S(I V)}\right)$, the bubbling or reaction time $\left(t_{\text {air }}\right)$ and the flowrate of air $\left(v_{\text {air }}\right)$. It was also confirmed that the $\mathrm{pH}$ of the samples did not change during the overall process. The removal efficiency is defined as the percentage decrease of COD and denoted by CODR\%. In the absence of Fe(II)/Fe(III) and S(IV), COD was not reduced by purging the samples with air. This clearly confirms that the removal of COD is not the consequence of the elimination of volatile organic compounds by purging. In another set of control experiments, iron(III) was added to the sample without sulfur(IV). The lack of COD removal verifies that coagulation induced by $\mathrm{Fe}(\mathrm{III})$ is not efficient for eliminating the contaminants under such conditions. Representative results when $C O D R \%$ is plotted as a function of one of the previously mentioned parameters while keeping others constant are shown in Fig.s 1-3 and S1-S3. It needs to be emphasized that these figures show overall trends which are somewhat altered when different sets of other parameters are used.

The removal efficiency reaches a constant value by increasing the duration of bubbling air, but $100 \%$ removal efficiency has never been reached (Fig. 1). This observation indicates that some of the components contributing to COD cannot be fully oxidized by this method. Furthermore, when S(IV) is completely consumed in the overall process the oxidation of the substrate is ceased.

The removal efficiency first increases and eventually sharply drops as the air flow is increased. (Fig. S1). In this case two factors need to be considered. First, the reaction mixture is getting increasingly oversaturated with oxygen and the alteration of the oxygen concentration has a profound effect on the rates of the competing reactions. In addition, air may purge S(IV) from the reaction mixture at high flow rates. Regardless of the other parameters, the optimum flow rate was at around $v_{\text {air }}=200 \mathrm{~mL} / \mathrm{min}$, therefore, this parameter was not altered in subsequent experiments.

As expected, CODR\% increases by increasing the concentration of $\mathrm{S}$ (VI). However, it is a unique feature that measurable decrease of COD is not observed up to a threshold concentration level of S(IV) which depends on the concentration of added Fe(II) (Fig. 2). This observation suggests that S(IV) should be used at relatively high concentration level.

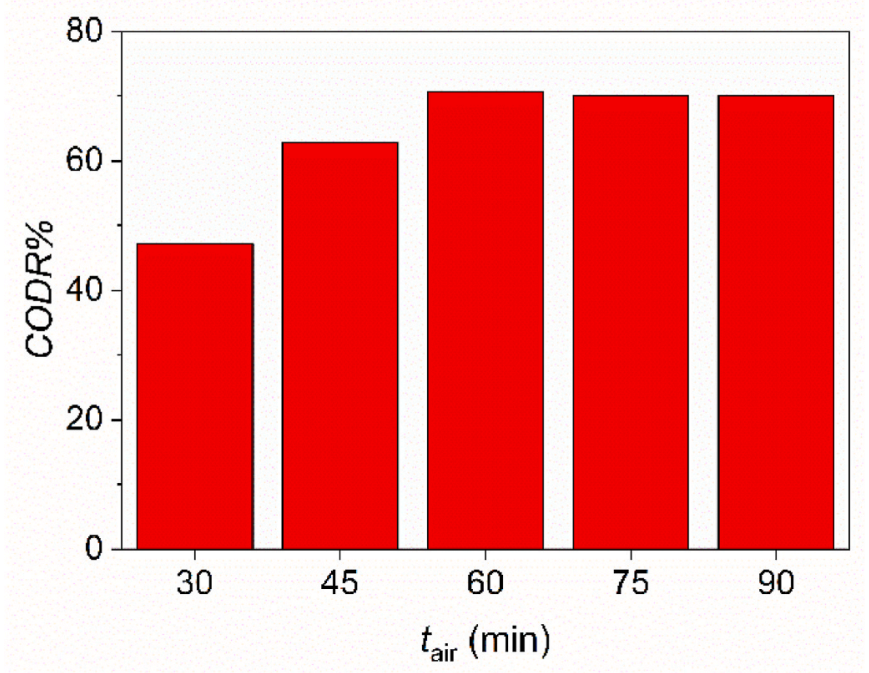

Fig. 1. The removal efficiency of COD as a function of bubbling time. $c_{\mathrm{Fe}}=4.0$ $\mathrm{mM}, \mathrm{Fe}(\mathrm{II}) \%=100 \%, c_{\mathrm{S}(\mathrm{IV})}=10.0 \mathrm{mM}, v_{\text {air }}=200 \mathrm{~mL} / \mathrm{min}$. 


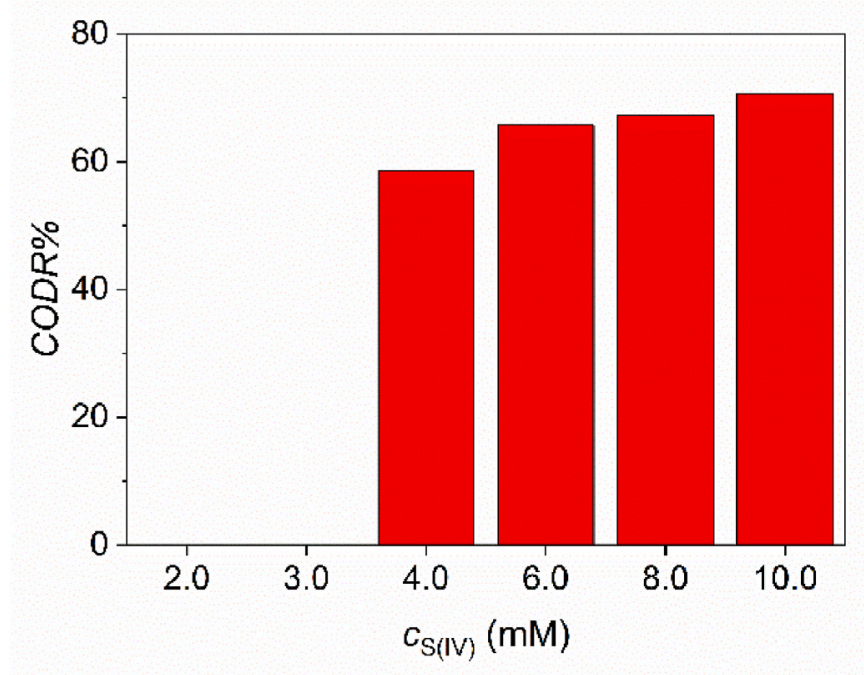

Fig. 2. The removal efficiency of COD as a function of $c_{\mathrm{S}(\mathrm{IV})} \cdot c_{\mathrm{Fe}}=4.0 \mathrm{mM}, \mathrm{Fe}$ (II) $\%=100 \%, t_{\text {air }}=60 \mathrm{~min}, v_{\text {air }}=200 \mathrm{~mL} / \mathrm{min}$.

However, S(IV) is fully converted into sulfate ion the concentration of which is limited to $2.5 \mathrm{mM}$ by drinking water regulations. Consequently, $c_{S(I V)}$ must not exceed $2.5 \mathrm{mM}$.

These results corroborate the conclusion that coagulation/adsorption phenomena have negligible contribution to COD removal, if at all. When $\mathrm{Fe}(\mathrm{II})$ is in excess over S(IV), the massive formation of the brownish Fe(III) hydroxo precipitate is observed due to the autooxidation of $\mathrm{Fe}(\mathrm{II})$. However, this process is not associated with measurable $C O D R \%$.

First, $C O D R \%$ increases by increasing $c_{\mathrm{Fe}}$ when only $\mathrm{Fe}(\mathrm{II})$ is added to the reaction mixture, then a falloff is observed (Fig. S2). The optimum total Fe(II) concentration depends on the total concentration of S(IV), i. e. the concentration ratio of these reactants also affects CODR\%. The noted trends are probably the consequence of Fe(III) formation which dominates the initial phase of the reaction. This possibility was tested by simultaneous addition of Fe(II) and Fe(III) to the reaction mixture. As shown in Fig. 3, CODR\% strongly depends on the initial concentration ratio of $\mathrm{Fe}(\mathrm{II})$ and $\mathrm{Fe}(\mathrm{III})$ when the total concentrations of iron and S(IV) are kept constant. Increasing the relative concentration of $\mathrm{Fe}(\mathrm{III})$ is

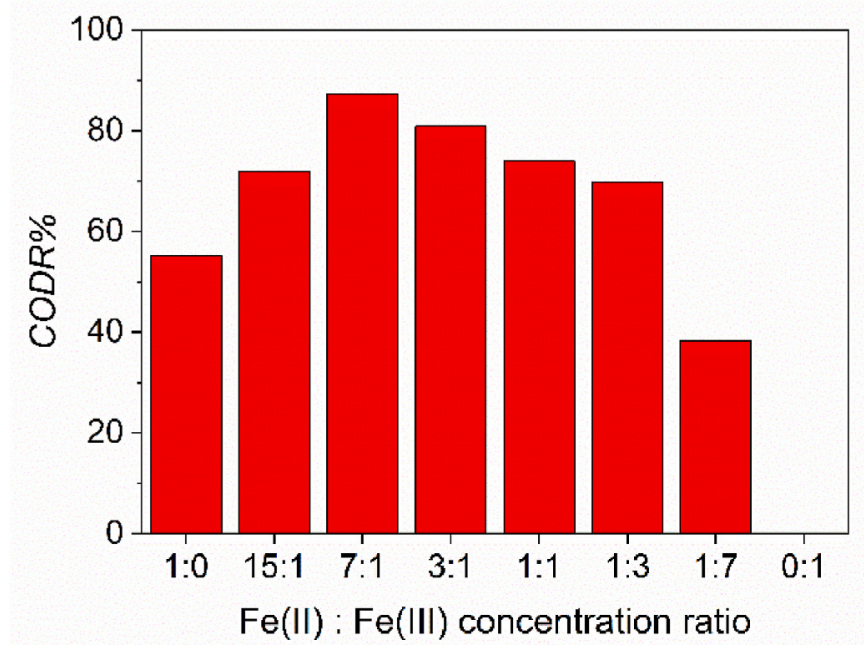

Fig. 3. The removal efficiency of COD as a function of the Fe(II) to Fe(III) concentration ratio when the total concentrations of iron and S(IV) are kept constant. $c_{\mathrm{Fe}}=2.0 \mathrm{mM}, c_{\mathrm{S}(\mathrm{IV})}=2.5 \mathrm{mM}, t_{\mathrm{air}}=60 \mathrm{~min}, v_{\mathrm{air}}=200 \mathrm{~mL} / \mathrm{min}$. beneficial for a while, but it is counterproductive when the concentration ratio of $\mathrm{Fe}(\mathrm{II})$ : $\mathrm{Fe}(\mathrm{III})$ goes below $7: 1$. It was also confirmed that the total iron concentration cannot be increased above a certain limit even when the optimum Fe(II): Fe(III) concentration ratio is maintained because of a distinct drop in the removal efficiency (Fig. S3).

All of these observations can be rationalized by considering Scheme 1. There are two main competing reactive paths in this very complex reaction system. One is the oxidation of S(IV) to sulfate ion and the other is the oxidation of the substrates and simultaneous regeneration of S(IV). The actual outcome of the overall process is determined by the interplay of these reactions. The rate of an individual reaction step strongly depends upon the reactant concentrations and concentration ratios. Apparently, the Fe(II) - Fe(III) redox cycle has a central role in this system. When only Fe(II) is added, first Fe(III) needs to be generated at sufficient concentration level. This process presumably consumes S(IV) and, as a consequence, decreases the efficiency when Fe(II) is used in high concentration. For the very same reason, CODR\% increases when initially $\mathrm{Fe}(\mathrm{III})$ is also added. It is also clear that there must be a very delicate balance between the concentrations of $\mathrm{Fe}(\mathrm{II})$ and $\mathrm{Fe}$ (III) because increasing the relative concentration of the latter one leads to a definite decrease in the efficiency. The results also confirm that the increased level of iron promotes the oxidation of S(IV) over the oxidation of the substrates.

\subsection{The optimization of the experimental parameters by Response Surface Methodology}

The Response Surface Methodology (RSM) utilizes statistical methods to predict the optimum values for a set of parameters in a complex process.(Bezerra et al., 2008; Elek et al., 2005; Hasan et al., 2011; Khoshnamvand et al., 2018; Murdani et al., 2018; Xie et al., 2016). The method can efficiently be used to reduce the number of experiments required for finding the desired operational conditions.

In this study, the plan of runs for optimizing CODR\% is in accordance with the face centered-central composite design (FC-CCD) by confining $c_{\mathrm{Fe}}, \mathrm{Fe}(\mathrm{II}) \%, c_{\mathrm{S}(\mathrm{IV})}$ and $t_{\mathrm{air}}$ in the ranges of $1.0-4.5 \mathrm{mM}, 0-100 \%, 0.5-2.5$ $\mathrm{mM}$ and $30-90 \mathrm{~min}$, respectively. In the case of $c_{\mathrm{S}(\mathrm{IV})}$, it needs to be considered that $\mathrm{S}$ (IV) is fully converted into sulfate ion during the process. According to current regulations, the concentration of sulfate ion cannot exceed $2.5 \mathrm{mM}$ in drinking water. Therefore, we limited the maximum concentration of S(IV) to $2.5 \mathrm{mM}$. The flow rate of air was kept constant at its optimum under most of the conditions $(200 \mathrm{~mL} /$ $\mathrm{min})$. The four independent factors $\left(\mathrm{X}_{1}, \mathrm{X}_{2}, \mathrm{X}_{3}, \mathrm{X}_{4}\right)$ corresponding to the above parameters were coded at three levels between -1 and +1 .

In accordance with FC-CDD, 21 experiments were performed. The experimental conditions and the corresponding CODR\% are listed in Table 1 . The removal efficiency varies in the range of $0.03-87.5 \%$. Five replicate runs were carried out at the center point to access the error of the method in randomized order as required by most of the design protocols. The excellent agreement of the CODR\% values in runs 5, 6, 12, $17,18(80.69-80.83 \%)$ demonstrates that the applied method yields highly reproducible result.

The response parameter (CODR\%) was fitted to a cubic approximation model, eq. (1), and evaluated by using the ANOVA analysis (Stahle and Wold, 1989).

$\mathrm{Y}=\mathrm{b}_{0}+\mathrm{b}_{1} \mathrm{X}_{1}+\mathrm{b}_{2} \mathrm{X}_{2}+\mathrm{b}_{3} \mathrm{X}_{3}+\mathrm{b}_{4} \mathrm{X}_{4}+\mathrm{b}_{12} \mathrm{X}_{1} \mathrm{X}_{2}+\mathrm{b}_{13} \mathrm{X}_{1} \mathrm{X}_{3}+\mathrm{b}_{14} \mathrm{X}_{1} \mathrm{X}_{4}$ $+b_{23} X_{2} X_{3}+b_{24} X_{2} X_{4}+b_{34} X_{3} X_{4}+b_{11} X_{1}^{2}+b_{22} X_{2}^{2}+b_{33} X_{3}^{2}+b_{44} X_{4}^{2}+$ $b_{123} X_{1} X_{2} X_{3}+b_{234} X_{2} X_{3} X_{4}+b_{124} X_{1} X_{2} X_{4}+b_{134} X_{1} X_{3} X_{4}+b_{112} X_{1}^{2} X_{2}+$ $b_{113} X_{1}^{2} X_{3}+b_{114} X_{1}^{2} X_{4}+b_{122} X_{1} X_{2}^{2}+b_{133} X_{1} X_{3}^{2}+b_{144} X_{1} X_{4}^{2}+b_{223}$ $\mathrm{X}_{2}^{2} \mathrm{X}_{3}+\mathrm{b}_{224} \mathrm{X}_{2}^{2} \mathrm{X}_{4}+\mathrm{b}_{233} \mathrm{X}_{2} \mathrm{X}_{3}^{2}+\mathrm{b}_{244} \mathrm{X}_{2} \mathrm{X}_{4}^{2}+\mathrm{b}_{334} \mathrm{X}_{3}^{2} \mathrm{X}_{4}+\mathrm{b}_{344} \mathrm{X}_{3} \mathrm{X}_{4}^{2}$ $+b_{111} X_{1}{ }^{3}+b_{222} X_{2}{ }^{3}+b_{333} X_{3}{ }^{3}+b_{444} X_{4}{ }^{3}$

Statistical analysis of the results provided the F- and P-values for the parameters (Table S2). Coefficients $\mathrm{R}^{2}(1.0000)$, adjusted $\mathrm{R}^{2}\left(\mathrm{R}^{2}\right.$ adj $=$ 1.0000) and the F-value for the model $\left(3.62110^{5}\right)$ confirm that the use 
Table 1

The experimental conditions in accordance with FC-CCD and the corresponding removal efficiency.

\begin{tabular}{llllll}
\hline Run & $c_{\mathrm{Fe}}(\mathrm{mM})$ & $\mathrm{Fe}(\mathrm{II}) \%(\%)$ & $c_{\mathrm{S}(\mathrm{IV})}(\mathrm{mM})$ & $t_{\mathrm{air}}(\mathrm{min})$ & CODR\% \\
\hline 1 & 1.70 & 20 & 0.9 & 42 & 87.3 \\
2 & 2.80 & 0 & 1.5 & 60 & 0.03 \\
3 & 4.50 & 50 & 1.5 & 60 & 0.03 \\
4 & 2.80 & 50 & 2.5 & 60 & 46.6 \\
5 & 2.80 & 50 & 1.5 & 60 & 80.8 \\
6 & 2.80 & 50 & 1.5 & 60 & 80.7 \\
7 & 3.80 & 80 & 0.9 & 42 & 0.03 \\
8 & 2.80 & 50 & 1.5 & 90 & 77.1 \\
9 & 1.00 & 50 & 1.5 & 60 & 66.9 \\
10 & 2.80 & 50 & 0.5 & 60 & 0.03 \\
11 & 3.80 & 80 & 0.9 & 78 & 0.03 \\
12 & 2.80 & 50 & 1.5 & 60 & 80.8 \\
13 & 1.70 & 80 & 2.1 & 78 & 79.7 \\
14 & 1.70 & 20 & 0.9 & 78 & 87.5 \\
15 & 3.80 & 20 & 2.1 & 78 & 66.5 \\
16 & 1.70 & 80 & 2.1 & 42 & 78.4 \\
17 & 2.80 & 50 & 1.5 & 60 & 80.8 \\
18 & 2.80 & 50 & 1.5 & 60 & 80.8 \\
19 & 3.80 & 20 & 2.1 & 42 & 60.6 \\
20 & 2.80 & 50 & 1.5 & 30 & 42.5 \\
21 & 2.80 & 100 & 1.5 & 60 & 54.8 \\
\hline
\end{tabular}

of the cubic model is adequate in this case. The correlation between predicted and experimental CODR\% with $\mathrm{p}<0.0001$ (Fig. S4) also confirms the reliability of the model.

The predictions of the model are illustrated by 3D response surface plots. As an example, the predicted $C O D R \%$ as a function of $c_{\mathrm{Fe}}$ and $c_{\mathrm{S}(\mathrm{IV})}$ is shown in Fig. 4. (Fig.s S5 - S9 present additional surface response plots.)

The RSM calculations also demonstrate the complexity of the system. As shown in Fig. 5, CODR\% does not change monotonously by increasing $c_{\mathrm{Fe}}$ and $c_{\mathrm{S}(\mathrm{IV})}$. The contour plot reveals two favorable regions (red zones) at relatively small and high reactant concentrations. Most likely, the oxidative removal of S(IV) becomes dominant over catalytic oxidation of the substrate in the intermediate region (green zone). In agreement with the results in Table 1, no COD removal is predicted in certain concentration domains (blue zones).

The statistical procedure predicts the following optimized conditions at 0.880 desirability level: $c_{\mathrm{Fe}}=1.7 \mathrm{mM}, \mathrm{Fe}$ (II) $\%=20 \% c_{\mathrm{S} \text { (IV) }}=0,9 \mathrm{mM}$ and $t_{\text {air }}=42 \mathrm{~min}$. To some extent, these results are unexpected because the systematic concentration dependent studies predict that Fe(II) needs to be used in excess over Fe(III) (cf. Fig. 3). However, those measurements were made at relatively high concentration of S(IV). Obviously, a systematic multi-dimensional optimization protocol by varying each parameter in a broad range while keeping other parameters constant could have provided the same result. The use of RSM circumvents this problem and provides reliable predictions on the basis of much fewer experiments. Under the predicted optimum conditions the measured and calculated values for CODR\% are $87.5 \%$ and $85.4 \%$, respectively. This excellent agreement confirms the validity of the model.

The robustness of the COD removal efficiency was tested by varying the concentrations of the reactants by $\pm 20 \%$ around the optimum parameter values at the same reaction time (42 $\mathrm{min})$. This variation results in some change in CODR\% but the removal efficiency remains satisfactorily good (Table S3).

In order to test the applicability of the method presented here, we investigated the COD removal efficiency with different source waters (obtained from Pocsaj, Biharkeresztes, Kismarja, Földeák, Apátfalva, Nagyér and Makó) using the optimum parameter values established for the source water from Királyhegyes. Table 2 lists the corresponding CODR\% which varied between 62.0 and $88.5 \%$. The parameters were not optimized for the individual source waters, still remarkable COD removal efficiencies were found. This indicates the robustness of the method again and proves that it can universally be used for substantial COD removal from source waters. In a few cases, the COD of the source water was below the allowed limit $(5 \mathrm{mg} / \mathrm{L})$ prior treatment. The corresponding experiments were carried out to demonstrate that a substantial portion of the pollutants can also be oxidized by the S(IV)-Fe(II)/ $\mathrm{Fe}(\mathrm{III})$-air system in these waters. This might be of significance when, for whatever reason, the operator of a water treatment plant aims to reduce COD substantially below the regulated limit.

\section{Conclusions}

Chemical oxygen demand (COD) in source waters presents a major challenge for drinking water treatment plants. The method presented here offers a versatile alternative for decreasing COD compared to other techniques used before. The main advantage of this process is that only low toxicity products form from the applied reagents: iron(III) and sulfate ion. Most importantly, the concentrations of the reagents and the final products are way below the regulatory limit after the treatment. Iron is transferred into precipitate which can be removed in later steps of the water treatment technology and the added sulfur(IV) is completely oxidized to sulfate ion in the process. In this study, the source waters were used as received, i.e. no pretreatment is required to achieve high efficiency COD removal. The use of Fe(II)/Fe(III) - S(IV) - air treatment in the early stage of drinking water production is also expected to reduce the risk of the formation of antagonistic products in further steps of the overall technology.

\section{Credit author statement}

Alexandra Truzsi: Investigation; Methodology; Data curation; Writing - original draft. János Elek: Formal analysis; Software; Validation; Visualization; István Fábián: Conceptualization; Funding acquisition; Resources; Supervision; Writing - original draft.

Table 2

The COD removal efficiency of the Fe(II)/Fe(III) - S(IV) - air system in different source waters. Some of the characteristic parameters are also listed.

\begin{tabular}{|c|c|c|c|c|c|c|c|c|c|}
\hline Location & $\mathrm{COD}(\mathrm{mg} / \mathrm{L})$ & $\begin{array}{l}\text { CODR } \\
\%(\%)\end{array}$ & $\mathrm{pH}$ & $\mathrm{NH}_{4}^{+}(\mathrm{mg} / \mathrm{L})$ & $\mathrm{Fe}(\mu \mathrm{g} / \mathrm{L})$ & $\operatorname{Mn}(\mu \mathrm{g} / \mathrm{L})$ & As $(\mu \mathrm{g} / \mathrm{L})$ & $\mathrm{CH}_{4}\left(\mathrm{~L} / \mathrm{m}^{3}\right)$ & $T\left({ }^{\circ} \mathrm{C}\right)$ \\
\hline Királyhegyes & 7.02 & 87.5 & 8.2 & 1.11 & 97.5 & 22.1 & 7.70 & 7.16 & 18.5 \\
\hline Apátfalva (Well III.) & 5.08 & 88.5 & 8.0 & 1.39 & 75.8 & 16.1 & 3.09 & 4.46 & 22.1 \\
\hline Apátfalva (Well IV.) & 6.91 & 88.1 & 8.0 & 1.19 & 106.6 & 149.4 & 1.90 & 7.77 & 19.7 \\
\hline Biharkeresztes (Well III.) & 7.88 & 62.0 & 7.9 & 1.03 & 87.0 & 43.0 & 25.1 & 23.3 & 24.0 \\
\hline Földeák (Well III.) & 2.70 & 85.5 & 8.0 & 1.58 & 151.1 & 22.6 & 21.9 & 2.47 & 31.1 \\
\hline Kismarja (Well II.) & 7.02 & 81.8 & 7.9 & 0.71 & 138.0 & 78.0 & $<0.5$ & - & 13.8 \\
\hline Makó (Well. I-II-III.) & 2.16 & 85.4 & 7.8 & 1.56 & 129.1 & 37.8 & 34.8 & 3.45 & 26.3 \\
\hline Nagyér (Well IV.) & 3.20 & 87.8 & 8.0 & 0.20 & 774.0 & 161.0 & 25.1 & 1.7 & 14.8 \\
\hline Pocsaj (Well III.) & 6.16 & 81.0 & 8.0 & - & 84.0 & 38.0 & 5.3 & - & - \\
\hline Pocsaj (Well IV.) & 9.18 & 82.9 & 8.0 & 1.31 & 98.0 & 29.0 & $<0.5$ & - & 25.1 \\
\hline
\end{tabular}

$c_{\mathrm{Fe}}=1.7 \mathrm{mM}, \mathrm{Fe}(\mathrm{II}) \%=20 \%, c_{\mathrm{S}(\mathrm{IV})}=0.9 \mathrm{mM} t_{\mathrm{air}}=42 \mathrm{~min}, v_{\mathrm{air}}=200 \mathrm{~mL} / \mathrm{min}$. 


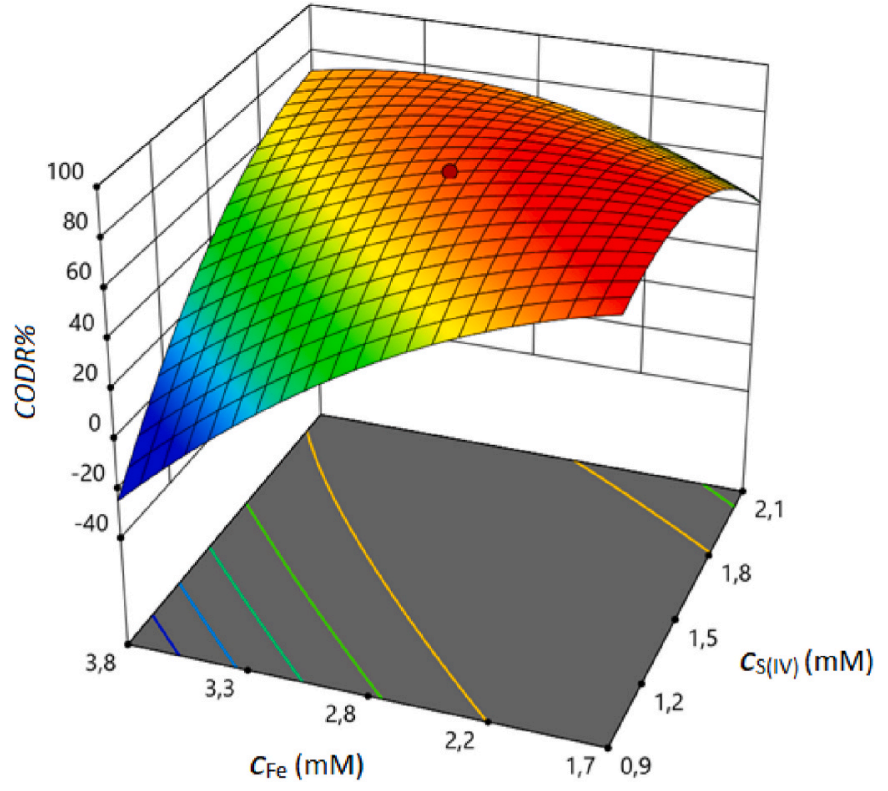

Fig. 4. Response surface for COD removal as a function of total Fe and S(IV) concentration. The colors indicate the efficiency of removal as follows, red: high, yellow: good, green: poor, blue: very poor or none. $\mathrm{Fe}(\mathrm{II}) \%=50 \%, t_{\mathrm{air}}=$ $60 \mathrm{~min}, v_{\text {air }}=200 \mathrm{~mL} / \mathrm{min}$. (For interpretation of the references to color in this figure legend, the reader is referred to the Web version of this article.)

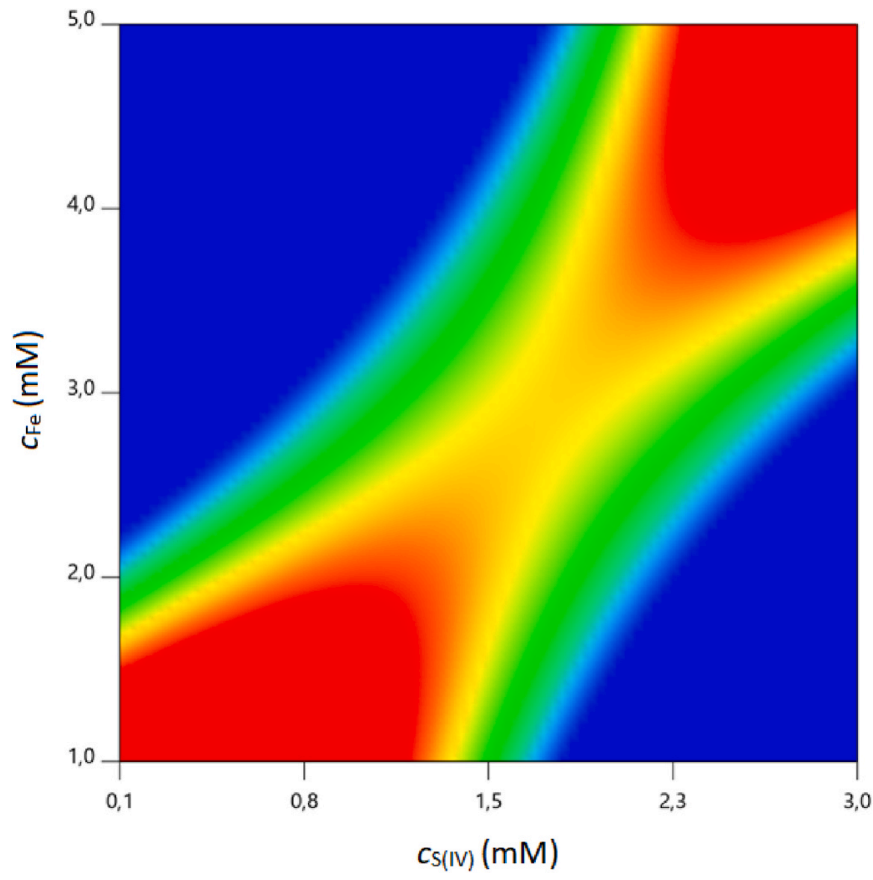

Fig. 5. Contour plot of COD removal as a function of total Fe and S(IV) concentration. The colors indicate the efficiency of removal as follows, blue: $0 \%$, red: high ( $85.4 \%$ at the optimum) $\mathrm{Fe}(I I) \%=20 \%, t_{\text {air }}=42 \mathrm{~min}, v_{\text {air }}=200 \mathrm{~mL} /$ min. (For interpretation of the references to color in this figure legend, the reader is referred to the Web version of this article.)

\section{Declaration of competing interest}

The authors declare that they have no known competing financial interests or personal relationships that could have appeared to influence the work reported in this paper.

\section{Acknowledgement}

This study was supported by the National Research, Development and Innovation Fund of Hungary under grant number OTKA-124983.

\section{Appendix A. Supplementary data}

Supplementary data to this article can be found online at https://doi. org/10.1016/j.envpol.2021.118625.

\section{References}

Alsheyab, M.A., Muñoz, A.H., 2007. Comparative study of ozone and $\mathrm{MnO}_{2} / \mathrm{O}_{3}$ effects on the elimination of TOC and COD of raw water at the Valmayor station. Desalination 207, 179-183. https://doi.org/10.1016/j.desal.2006.07.010.

Baken, K.A., Sjerps, R.M.A., Schriks, M., van Wezel, A.P., 2018. Toxicological risk assessment and prioritization of drinking water relevant contaminants of emerging concern. Environ. Int. 118, 293-303. https://doi.org/10.1016/j.envint.2018.05.006.

Bezerra, M.A., Santelli, R.E., Oliveira, E.P., Villar, L.S., Escaleira, L.A., 2008. Response surface methodology (RSM) as a tool for optimization in analytical chemistry. Talanta 76, 965-977. https://doi.org/10.1016/j.talanta.2008.05.019.

Brandt, C., Fábián, I., van Eldik, R., 1994. Kinetics and mechanism of the iron(III) catalyzed autoxidation of sulfur(IV) oxides in aqueous solution - evidence for the redox cycling of iron in the presence of oxygen and modelling the overall reaction mechanism. Inorg. Chem. 33, 687-701. https://doi.org/10.1021/ic00082a012.

Chen, L., Xue, Y., Luo, T., Wu, F., Alshawabkeh, A.N., 2021. Electrolysis-assisted UV/ sulfite oxidation for water treatment with automatic adjustments of solution $\mathrm{pH}$ and dissolved oxygen. Chem. Eng. J. 403, 126278. https://doi.org/10.1016/j. cej.2020.126278.

Council of the European Union, 2020. Directive (EU) of the European Parliament and of the Council on the Quality of Water Intended for Human Consumption (Brussels). htt ps://data.consilium.europa.eu/doc/document/ST-6230-2020-REV-3/en/pdf.

Dong, H., Wei, G., Yin, D., Guan, X., 2020. Mechanistic insight into the generation of reactive oxygen species in sulfite activation with $\mathrm{Fe}(\mathrm{III})$ for contaminants degradation. J. Hazard Mater. 384, 121497. https://doi.org/10.1016/j. jhazmat.2019.121497.

Elek, J., Mangelings, D., Ivanyi, T., Lazar, I., Heyden, Y.V., 2005. Enantioselective capillary electrophoretic separation of tryptophane- and tyrosine-methylesters in a dual system with a tetra-oxadiaza-crown-ether derivative and a cyclodextrin. J. Pharmaceut. Biomed. Anal. 38, 601-608. https://doi.org/10.1016/j. jpba.2005.02.014.

Franklin, H.M., Doederer, K., Neale, P.A., Hayton, J.B., Fisher, P., Maxwell, P., Carroll, A. R., Burford, M.A., Leusch, F.D.L., 2021. Terrestrial dissolved organic matter source affects disinfection by-product formation during water treatment and subsequent toxicity. Environ. Pollut. 283, 117232. https://doi.org/10.1016/j. envpol.2021.117232.

Geerdink, R.B., Sebastiaan van den Hurk, R., Epema, O.J., 2017. Chemical oxygen demand: historical perspectives and future challenges. Anal. Chim. Acta 961, 1-11. https://doi.org/10.1016/j.aca.2017.01.009.

Gitis, V., Hankins, N., 2018. Water treatment chemicals: trends and challenges. J. Water Process Eng. 25, 34-38. https://doi.org/10.1016/j.jwpe.2018.06.003.

Guerra-Rodríguez, S., Cediel, N., Rodríguez, E., Rodríguez-Chueca, J., 2021. Photocatalytic activation of sulfite using Fe(II) and Fe(III) for Enterococcus sp. Inactivation in urban wastewater. Chem. Eng. J. 408, 127326. https://doi.org/ 10.1016/j.cej.2020.127326.

Hasan, H.A., Abdullah, S.R.S., Kamarudin, S.K., Kofli, N.T., 2011. Response surface methodology for optimization of simultaneous COD, $\mathrm{NH}_{4}{ }^{+}-\mathrm{N}$ and $\mathrm{Mn}^{2+}$ removal from drinking water by biological aerated filter. Desalination 275, 50-61. https:// doi.org/10.1016/j.desal.2011.02.028.

Huang, X., Zemlyanov, D.Y., Diaz-Amaya, S., Salehi, M., Stanciu, L., Whelton, A.J., 2020. Competitive heavy metal adsorption onto new and aged polyethylene under various drinking water conditions. J. Hazard Mater. 385, 121585. https://doi.org/10.1016/ j.jhazmat. 2019.121585.

Jha, M.K., Shekhar, A., Jenifer, M.A., 2020. Assessing groundwater quality for drinking water supply using hybrid fuzzy-GIS-based water quality index. Water Res. 179, 115867. https://doi.org/10.1016/j.watres.2020.115867.

Khoshnamvand, N., Kord Mostafapour, F., Mohammadi, A., Faraji, M., 2018. Response surface methodology (RSM) modeling to improve removal of ciprofloxacin from aqueous solutions in photocatalytic process using copper oxide nanoparticles $(\mathrm{CuO} /$ UV). AMB Express 8, 48. https://doi.org/10.1186/s13568-018-0579-2.

Kohler, S.J., Lavonen, E., Keucken, A., Schmitt-Kopplin, P., Spanjer, T., Persson, K., 2016. Upgrading coagulation with hollow-fibre nanofiltration for improved organic matter removal during surface water treatment. Water Res. 89, 232-240. https://doi.org/ 10.1016/j.watres.2015.11.048.

Kraft, J., van Eldik, R., 1989. The possible role of iron(III)-sulfur(IV) complexes in the catalyzed autoxidation of sulfur(IV)-oxides. A mechanistic investigation. Atmos. Environ. 23, 2709-2713. https://doi.org/10.1016/0004-6981(89)90550-7.

Latchmore, T., Hynds, P., Brown, R.S., Schuster-Wallace, C., Dickson-Anderson, S., McDermott, K., Majury, A., 2020. Analysis of a large spatiotemporal groundwater quality dataset, Ontario 2010-2017: informing human health risk assessment and testing guidance for private drinking water wells. Sci. Total Environ. 738, 140382. https://doi.org/10.1016/j.scitotenv.2020.140382. 
Lente, G., Fábián, I., 2002. Kinetics and mechanism of the oxidation of sulfur(IV) by iron (III) at metal ion excess. J. Chem. Soc., Dalton Trans. 778-784. https://doi.org/ 10.1039/b107263c.

Li, G., Wang, C., Yan, Y., Yan, X., Li, W., Feng, X., Li, J., Xiang, Q., Tan, W., Liu, F., Yin, H., 2020. Highly enhanced degradation of organic pollutants in hematite/ sulfite/photo system. Chem. Eng. J. 386, 124007. https://doi.org/10.1016/j. cej.2019.124007.

Matilainen, A., Sillanpaa, M., 2010. Removal of natural organic matter from drinking water by advanced oxidation processes. Chemosphere 80, 351-365. https://doi.org/ 10.1016/j.chemosphere.2010.04.067.

Mazhar, M.A., Khan, N.A., Ahmed, S., Khan, A.H., Hussain, A., Rahisuddin, Changani F., Youse, M., Ahmadi, S., Vambol, V., 2020. Chlorination disinfection by-products in municipal drinking water - a review. J. Clean. Prod. 273, 123159. https://doi.org/ 10.1016/j.jclepro.2020.123159.

Mtavangu, S., Rugaika, A.M., Hilonga, A., Njau, K.N., 2017. Performance of constructed wetland integrated with sand filters for treating high turbid water for drinking. Water Pract. Technol. 12, 25-42. https://doi.org/10.2166/wpt.2017.007.

Murdani, Jakfar, Ekawati, D., Nadira, R., Darmadi, 2018. Application of Response Surface Methodology (RSM) for wastewater of hospital by using electrocoagulation. In: 2nd International Conference on Oleo and Petrochemical Engineering (Icoopche 2017), vol. 345, 012011. https://doi.org/10.1088/1757-899x/345/1/012011.

Nie, G., Xiao, L., 2020. New insight into wastewater treatment by activation of sulfite with photosensitive organic dyes under visible light irradiation. Chem. Eng. J. 389, 123446. https://doi.org/10.1016/j.cej.2019.123446.

Noredinvand, B.K., Takdastan, A., Yengejeh, R.J., 2016. Removal of organic matter from drinking water by single and dual media filtration: a comparative pilot study. Desalin. Water Treat. 57, 20792-20799. https://doi.org/10.1080/ 19443994.2015.1110718.

Pan, R., Zhang, K., Cen, C., Zhou, X., Xu, J., Wu, J., Wu, X., 2021. Characteristics of biostability of drinking water in aged pipes after water source switching: ATP evaluation, biofilms niches and microbial community transition. Environ. Pollut. 271, 116293. https://doi.org/10.1016/j.envpol.2020.116293.

Postigo, C., Andersson, A., Harir, M., Bastviken, D., Gonsior, M., Schmitt-Kopplin, P., Gago-Ferrero, P., Ahrens, L., Ahrens, L., Wiberg, K., 2021. Unraveling the chemodiversity of halogenated disinfection by-products formed during drinking water treatment using target and non-target screening tools. J. Hazard Mater. 401 https://doi.org/10.1016/j.jhazmat.2020.123681.

Schmoll, O., Howard, G., Chilton, J., Chorus, I., 2006. Protecting Groundwater for Health, Managing the Quality of Drinking-Water Sources. WHO, IWA Publishing, London, UK.
Stahle, L., Wold, S., 1989. Analysis of variance (ANOVA). Chemometr. Intell. Lab. Syst. 6, 259-272. https://doi.org/10.1016/0169-7439(89)80095-4.

Stankov, V., Stankov, M.N., Cvetnić, M., Sigurnjak Bureš, M., Ukić, Š., Kučić Grgić, D., Lončarić Božić, A., Kušić, H., Bolanča, T., 2021. Environmental aspects of UV-Cbased processes for the treatment of oxytetracycline in water. Environ. Pollut. 277, 116797. https://doi.org/10.1016/j.envpol.2021.116797.

Sun, S., Jiang, T., Lin, Y., Song, J., Zheng, Y., An, D., 2020. Characteristics of organic pollutants in source water and purification evaluations in drinking water treatment plants. Sci. Total Environ. 733, 139277. https://doi.org/10.1016/j. scitotenv.2020.139277.

United Nations Economic Commission for Europe (UN-ECE), 1993. Readings in International Environment Statistics. In: Economic Commission for Europe. https://u nece.org/fileadmin/DAM/env/documents/1993/esc.pdf.

Wang, S.X., Wang, G.S., Fu, Y.S., Wang, H.B., Liu, Y.Q., 2020. A simple $\mathrm{Fe}^{3+} /$ bisulfite system for rapid degradation of sulfamethoxazole. RSC Adv. 10, 30162-30168. https://doi.org/10.1039/d0ra05962e.

World Health Organization, 2018. A global overview of national regulations and standards for drinking-water quality. In: World Health Organization. https://www. who.int/publications/i/item/9789241513760.

Wu, S., Shen, L., Lin, Y., Yin, K., Yang, C., 2021. Sulfite-based advanced oxidation and reduction processes for water treatment. Chem. Eng. J. 414, 128872. https://doi. org/10.1016/j.cej.2021.128872.

Xiao, Q., Yu, S., 2021. The role of dissolved oxygen in the sulfite/divalent transition metal ion system: degradation performances and mechanisms. Chem. Eng. J. 417, 129115. https://doi.org/10.1016/j.cej.2021.129115.

Xie, P., Zhang, L., Chen, J., Ding, J., Wan, Y., Wang, S., Wang, Z., Zhou, A., Ma, J., 2019. Enhanced degradation of organic contaminants by zero-valent iron/sulfite process under simulated sunlight irradiation. Water Res. 149, 169-178. https://doi.org/ 10.1016/j.watres.2018.10.078.

Xie, Y., Chen, L., Liu, R., 2016. Oxidation of AOX and organic compounds in pharmaceutical wastewater in RSM-optimized-Fenton system. Chemosphere 155, 217-224. https://doi.org/10.1016/j.chemosphere.2016.04.057.

Xu, R.Y., Xie, Y.W., Tian, J.P., Chen, L.J., 2021. Adsorbable organic halogens in contaminated water environment: a review of sources and removal technologies. J. Clean. Prod. 283 https://doi.org/10.1016/j.jclepro.2020.124645.

Zhou, D., Chen, L., Li, J., Wu, F., 2018. Transition metal catalyzed sulfite auto-oxidation systems for oxidative decontamination in waters: a state-of-the-art minireview. Chem. Eng. J. 346, 726-738. https://doi.org/10.1016/j.cej.2018.04.016. 